\title{
LIX. On the wolf-note in bowed stringed instruments
}

\section{C.V. Raman M.A.}

To cite this article: C.V. Raman M.A. (1918) LIX. On the wolf-note in bowed stringed instruments, Philosophical Magazine Series 6, 35:210, 493-496, DOI: 10.1080/14786440608635793

To link to this article: http://dx.doi.org/10.1080/14786440608635793

曲 Published online: 08 Apr 2009.

Submit your article to this journal $[\pi$

Џ Article views: 9

Q View related articles $\square$

Citing articles: 1 View citing articles 5 


\section{[ $\quad 493$ ]}

LIX. On the Wolf-note in Bowed Stringed Instruments. By C. V. Raman, M.A., Sir Taraknath Palit Professor of Physics in the Calcutta University*.

1. T $\mathrm{N}$ the Phil. Mag. for June 1917 (page 536), Mr. J. W. 1 Giltay has questioned the correctness of the remark. made by me in the Phil. Mag. for Oct. 1916 (page 394), that the explanation of the effect of a "mute" on the tone of bowed stringed instruments is chiefly to be sought for in the lowering of the frequencies of resonance of the instrument produced by the loading of the bridge.

2. Before replying to the specific issues raised by Mr. Giltay, I may be permitted to point out that the view of the action of the mute suggested by me rests upon the secure foundation of mathematical analysis. The effect of adding inertia to any part of a dynamical system has been considered by Lord Rayleigh, Routh and others, and it has been shown that the natural frequencies as altered by the addition of the load are given by the roots of the equation (see Routh's 'Advanced Rigid Dynamics,' Section 76)

$$
\left(\mathrm{N}_{1}{ }^{2}-n^{2}\right)\left(\mathrm{N}_{2}{ }^{2}-n^{2}\right) \& c .,-\alpha n^{2}\left(n_{2}{ }^{2}-n^{2}\right)\left(n_{3}{ }^{2}-n^{2}\right) \& c .=0 \text {, }
$$

In the above, $\mathrm{N}_{1}, \mathrm{~N}_{2}$, \&c. are the frequencies before the addition of load, $n_{1}, n_{2}, n_{3}$, \&c. are the limiting values of the frequencies attained when the load becomes infinitely large, and $x$ is a positive quantity proportionate to the added inertia.

$$
\begin{aligned}
& {\left[n_{1}=0, n_{2}>\mathrm{N}_{1}, n_{3}>\mathrm{N}_{2}, \& c\right. \text {., according to the theorem }} \\
& \text { due to Routh]. }
\end{aligned}
$$

The forced vibration due to a periodic force of frequency $n$ (assumed to act on the system at the point at which the load is fixed) also depends on the magnitude of the expression on the left-hand side of the preceding equation, being in fact inverscly proportional to it except in the immediate neighbourhood of the frequencies of resonance. The expression may, for convenience, be written in the form $(p-\alpha q)$. Assuming that the frequency $n$ of the impressed force lies between two of the natural frequencies, say $N_{1}$ and $\mathrm{N}_{2}$, of the system without any load, the effect of the load on the forced vibration evidently depends on whether $p$ and $q$ are of the same or of opposite sign. If $n$ be less than $n_{2}$, they are of opposite signs, while if $n$ be greater than $n_{2}$, they are of the same sign. In the former case, the load decreases the amplitude of the forced vibration throughout. In the

$$
\text { * Communicated by the Author. }
$$

Phil, Mag. S, 6. Vol. 35. No, 210, June 1918. 
latter case, the vibration is increased by the addition of load till the stage is reached at which $p=a q$, the amplitude then becoming very large. Subsequent additions of load decrease the forced vibration till it finally vanishes in the limit.

3. If, however, the point at which the load is fixed is not the same as that at which the impressed force acts on the system, the treatment is not equally simple. The expression for the forced vibration then obtained from the Lagrangian equations has the determinant for the free periods as its denominator; but the numerator contains some arlditional terms, the magnitude of which is proportional to the applied load. If these terms are ignored, the sequence of changes with increasing load would be exactly the same as that stated in the precedino paragraph.

4. 'There is no difficulty in verifying the foregoing indications of theory experimentally. In the case of the violin or 'cello, at least the first three of the natural modes of vibration of the instrument have to be taken into account to explain the phenomena produced by the mute within the ordinary range of tone of the instrument. The two first resonance-frequencies are those mentioned by Helmholtz in his work. The pitch of the first is only slightly lowered by the mute. The second is the well-known "wolf-note," and the pitch of this is depressed by about 450 cents by the mute. The pitch of the third resonance is about an octave higher than that of the second, and this also gives a marked "wolf-note." The mute lowers the pitch of this by about 700 cents. The mass of an ordinary brass mute is sufficient to make the second, third, and higher resonance-frequencies approximate to their limiting values. The effect of the mute should accordingly be to increase the intensity of the graver tones and barmonies of the instrument, and to decrease those of high pitch. This is exactly what has been found experimentally by Edwards (Physical Review, Jan. 1911).

5. Mr. Giltay's criticisms may now be easily disposed of. Experiment shows that he is incorrect in saying "I suppose that the change of pitch of the note of maximum resonance of bridge, belly, \&c. will practically be the same whether the bridge be loaded at its highest point or as low as possible and near to its left foot." "As a matter of fact, trial shows that the lowering of the pitch of either of the two "wolfnotes" is three to five times as much in the former case as in the latter. As the observed mute-effect is less when the load is placed at the foot of the bridge, the experiment actually furnishes a strong confirmation of the correctness of my views, and shows also that the interpretation given by 
Giltay and $\mathrm{D}_{3}$ Hras to their observations (Proc. Roy. Soc. Ainsterdam, January 1910) requires revision. As a matter of fact, it appears from my detailed observations that Giltay and De Haas were in error in assuming that the motion of the bridge in its own plane is practically that of a rigid body. Owing to the form of the bridge, the cuts in it, \&c., this is very far indeed from being the case, the elastic distortions heing very large. For instance, it makes all the difference in the pitch of the wolf if a load be fred immediately above instead of immediately below the cut on the G-string side of the bridge. This fact is inconsistent with the supposition made by Giltay and De Haas that the motion of the bridge in its own plane is one of simple rotation about an axis, and proves that the theory of the action of the mnte put forward by these writers is untenable.

6. In view of what has been said in para. 4 , the observed muting of the high notes of the instrument which Mr. Giltay suggests as a difficulty, is easily seen to be exactly what is to be expected according to the view of the action of the mute put forward by me. In the absence of a mute, the resonance of the violin is by far the strongest at the pitch of the two wolf-notes. Theory thus indicates that the quality of violin-tone and the effect of a mute upon it may be characterized as follows : the gravest tones have a weak fundamental with strong second and third harmonics, muting increasing the fundamental at the expense of the harmonics: in the middle of the scale the tones should have strong fundamental and second harmonic with relatively weak higher harmonics, all except the fundamental being decreased by muting; the highest tones should have strong fundamental and weak upper partials, all the components being decreased by muling. The observations of Hewlett (Physical Review, Nov. 1912) and those of Edwards already quoted are in substantial agreement with the above.

7. Another interesting question which arises regarding the action of the mute is its effect on the minimum bowing pressure necessary in order to elicit a steady vibration of the usual type. I have investigated this question theoretically by considering the effect of the mute on the motion of the bridge and consequently on the mivimum frictional force which should be exerted by the bow on the string in orler that a stearly vibration should be possible. The question has also been studied experimentally using a mechanica! player in which an crdinary violin-bow excites the strings of a violin under stricrly controlled pressure and relocity of movement. The quantitative data obtained clearly show the $2 \mathrm{M} 2$ 
great increase in the bowing pressure which becomes necessary at the wolf-note pitch, and prove that the effect of the mute is to increase the bowing pressure necessary at low frequencies and to decrease it at high frequencies. With this mechanical player, the "cyclical" or "beating" tones obtained in certain cases (Phil. Mag. Oct. 1916 and Feb. 1917) may be steadily maintained and controlled by suitable adjustment of the bowing pressure.

Indian Association for the

Cultivation of Science, Calcutta.

LX. On a New Type of Rough Surface the Motion of a Heavy Particle on which is determinable by Quadratures. By Nalinimohan Basu, M.Sc., University Lecturer in Applied Mathematics, Calcutta*.

1. $\mathrm{T}$ is well known that the motion of a heavy particle on 1 a rough surface is determinable by quadratures when the surface is an inclined plane, a circular cylinder, a circular cone, or a vertical cylinder standing on a logarithmic spiral as the base $\dagger$.

The object of the present paper is to make known another surface which has, in a certain sense, the same property as the four surfaces mentioned above and which, it is believed, has not been considered by any previous writer.

2. Let us consider the surface whose equation is

$$
\chi \equiv z-\tan \alpha \cdot \tan ^{-1} \frac{y}{x}-\left(x^{2}+y^{2}-1\right) \mathrm{P}(z)=0,
$$

where $\mathrm{P}(z)$ is given by the relation

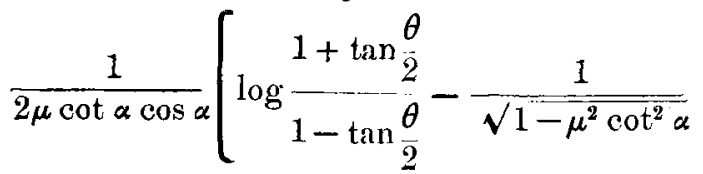

$$
\begin{aligned}
& \left.\times \log \frac{\sqrt{1-\mu \cot \alpha}+\sqrt{1+\mu \cot \alpha} \cdot \tan \frac{\theta}{2}}{\sqrt{1-\mu \cot \alpha}-\sqrt{1+\mu \cot \alpha} \cdot \tan \frac{\theta}{2}}\right)=z-h, .
\end{aligned}
$$

$\tan \theta$ standing for $2 \mathrm{P} \cos \alpha$ and the axis of $z$ being drawn vertically upwards.

* Communicated by Prof. G. Prasad.

$\uparrow$ For the first three cases, see any well lnnown text-book on the "Dynamics of a Particle," e.g. Routh's book; for the last case, see A. Razzaboni's paper, "Sul movimento d'un punto materiale sopra una superficie non levigatu." (Giornale di matematiche, vol, xxxiv.) 